\title{
Characterizing Idiomatic Organization in Music: A Theory and Case Study of Musical Affordances
}

\author{
DAVID HURON ${ }^{[1]}$ \\ School of Music, Ohio State University \\ JONATHON BEREC \\ University of Waterloo
}

\begin{abstract}
A theory of idiomaticism is developed and illustrated using music for Bflat valve trumpet. Physical measures were collected from two trumpet performers and used to construct a computer model of the instrument/performer. Using this model, several works composed by both trumpet virtuosi and non-trumpet players were analyzed. A conceptual distinction is made between measures of performance difficulty (how hard it is to play a particular passage) and measures of performance idiomaticism (how well suited a passage is to a specific instrument). Methods for characterizing both difficulty and idiomaticism are described. In general, the results suggest that detailed modeling of the mechanics of performance can help to pinpoint aspects of musical organization that arise from performance idioms or affordances. Repercussions for ethnomusicology, historical musicology and music analysis are discussed.
\end{abstract}

Submitted 2009 June 8; accepted 2009 July 15.

KEYWORDS: idiomaticism, performance, difficulty, modeling, Gebrauchmuzik

AN idiom may be defined as a form of expression unique to a given language, mode of interaction, or physical circumstance. The Greek root of the word idiom suggests something personal, unique, or peculiar. In modern English usage, the word idiom is associated with vernacular expressions or sayings. Linguistic idioms, for example, include common phrases that cannot normally be translated directly from one language to another - such as "face the music," "music to my ears," or "pull out all the stops." Within a given language community, different speakers can often be characterized as more or less idiomatic depending on the extent to which their speech relies on the use of idiomatic expressions.

In music, the concept of idiom has been applied to a wide variety of phenomena; however, the term is commonly associated with the use of distinctive instrumental resources. The mechanics of musical instruments commonly influence how the music itself is organized. Like spoken utterances, musical passages can be characterized as more or less idiomatic depending on the extent to which the music relies on instrument-specific effects.

Ethnomusicologists frequently point to instrumental idioms as having had marked impacts on the character of music-making in different cultures (e.g., Baily, 1985; DeWitt, 1998; Yu, 1977; Yung, 1980). Similarly, historical musicologists have often pointed to physical characteristics of performance, especially in relation to arrangements of musical works made for different instrumentation (e.g., Dreyfus, 1998; Le Guin, 1997; Mohr, 1972; Morehen, 1994; Parkins, 1983; Shepherd, 1995; Shao, 1997; Ung, 1981). Jazz and blues musicians often stress the importance of idiomatic instrumental techniques in improvisation (e.g., Richardson, 1996; Sudnow, 1978, 1979; Walser, 1993). Electroacoustic musicians can identify the vintage of electronic works by the characteristic sounds or gestures associated with specific hardware devices or formerly popular algorithms (e.g., Henry, 1970). Musical genres have been identified in which the idiomatic aspects of one sound source are imitated by another - such as the vocal imitation of the Greek gaida bagpipe by traditional singers (Sarris \& Tzevelekos, 2008). Musical idiomaticism has been addressed in a variety of descriptive and statistical ways by music scholars (Horton, 1986; Jiranek, 1971).

The musical concept of "idiomatic" is closely related to Jakob von Uexküll's (1920) notion of funktionale Tönung (functional coloring) and James Gibson's (1977) notion of affordances. In both cases, the idea is that an object provides latent action possibilities and that the perception of an object may entail 
the apprehension of certain functions. A bird may recognize that a particular arrangement of branches provides a good opportunity for nest-building. For a human, the heft and size of a rock may lend itself well to throwing.

In recent decades, Gibson's concept of affordances has become widely influential, especially in the world of design. The concept was popularized through Donald Norman's 1988 book The Design of Everyday Things. Norman emphasized how good design can tell an inexperienced user how to correctly use an object without explicit instruction. For example, depending on how a door is designed, a looped handle might tell a user to "pull," whereas a horizontal bar might tell a user to "push." Written labels, such as "push" and "pull" are tacit acknowledgments of design failure, since the structure of the door itself should afford the appropriate action.

Despite their generality, both von Uexküll's and Gibson's notions are pre-dated by the musical concept of idiomaticism. For at least a century, organologists have described the properties of musical instruments and have discussed how these properties appear to suggest certain modes of interaction or encourage certain musical functions (e.g., Sachs, 1913). A stretched-membrane drum, for example, affords a number of sonic possibilities. The drum may be struck with a hand or with a stick; it may be struck by a single hand, by alternating hands, by drumming the fingers, etc. The drumhead may be depressed with one hand (modifying the tension) while striking with the other hand; the side of the drum may be struck, and so on. Large drums afford the opportunity to be played by more than one performer. Small drums may afford the opportunity for the player to dance. (In the latter case, notice that not all affordances relate to the creation of sound.)

The most distinctive instrumental idioms include gestures that are unique to a particular instrument. For example, a well-known solo trumpet passage at the end of Leroy Anderson's Sleigh Ride imitates the sound of a neighing horse. No other Western orchestral instrument can produce this sound so convincingly and so the effect may be said to be idiomatic to the trumpet. Using Gibsonian terminology, we might say that the trumpet affords the possibility of generating a sound that alludes to a neighing horse.

While idiomatic properties can be regarded as opportunities, in music, it has also been common to describe idiomatic properties as limitations. Perhaps the foremost idiomatic concern (encountered by musicians around the world) relates to the pitch range of an instrument or voice. When studying orchestration, composers first learn and memorize the ranges of various instruments. Similarly, a Persian musician might wonder whether a passage for Barbat might be playable on the Tar.

It is possible to conceive of a musical idea whose realization is impractical. If a musician or musical community holds an (abstract) musical conception or goal, an important question is whether this goal must be altered in order to accommodate the limitations imposed by some instrument. The contrast between Leroy Anderson's neighing horse and the perennial question of pitch range illustrates that idiomatic properties may be viewed as either inspirations or impediments.

Not all idiomatic properties relate to the mechanics or kinematics of a performer/instrument duo. Other limitations may arise due to practical difficulties in coordinating the actions of groups of people, such as may occur when there is a division of labors between musicians and dancers. Yet other limitations may relate to the performance venue or the social context. At a political demonstration, while visual messages are influenced by the physical size of placards and banners, chanted slogans are influenced by human memory and matters of group synchronization. In each case, the complexity of an expression may be limited or reshaped by a variety of aspects of the means of generation.

While idiomatic properties may be unique to a specific instrument, these properties are frequently shared by several instruments, and so a wider notion of instrumental idiom can also be identified. A given passage may be playable on a variety of musical instruments, but may be better suited to one particular type or class of instruments. For example, certain musical passages may be especially suited to plucked instruments such as the guitar or harp. However, the idiomatic similarities between instruments are not always obvious. For example, Bach's organ transcriptions of Vivaldi violin concertos reflect certain affinities between the organ and violin that are not immediately apparent - especially when compared to (say) hypothetical transcriptions of these same concertos for flute. Vivaldi's long melodic lines would leave a flautist struggling for air. Moreover, Vivaldi's frequent alternating figures (including unisons) between two violin strings are readily replicated using two organ manuals. These latter types of idiomatic features are more widespread than instrument-specific (neighing-horse variety) gestures - and so can be much more musically significant. However, since these idiomatic features are more subtle than neighing-horses, they can also be more difficult to identify. 
Music scholars have often drawn attention to idiomatic characteristics in various musical passages. For example, certain composers display idiomatic tendencies in their writing that purportedly arise from their skills as performers on a given instrument. Identifying idiomatic features can be important in the analysis of music since it may lead to insights pertaining to the poietic process. Idiomatic clues can lend weight to particular interpretations, such as, for example, that some symphonic work was initially conceived as a string quartet, or that a guitar work was influenced by the composer's habit of working out ideas on the piano. Conversely, the apparent absence of idiomatic features might suggest that a work originated in a non-instrumental conception, such as might occur when a work is inspired by religious, cultural, formal or abstract ideas.

In the present work, our overall aim is to identify when physical and kinematic aspects of instrumental performance are reflected in the organization of specific musical works. Identifying the extent to which a passage is idiomatic to a given instrument or instrumental combination poses both practical and theoretical challenges. Although some instances of idiomatic construction seem obvious, evidence in support of most claims of idiomatic writing are informal and impressionistic. In this study, we describe a generalized method for measuring the degree of idiomaticism in notated musical passages. Our aim is to show how empirical methods can be used to distinguish more idiomatic from less idiomatic works. Although the discussion will be restricted to the case of the B-flat valve trumpet, the overall approach described here could, in theory, be applied to any musical instrument. Note that the purpose of measuring idiomaticism is not to supplant the role of musical intuition in judging idiomatic treatment. Rather, the purpose of devising such a measure is to provide more refined and potentially convincing evidence in support of such idiomatic interpretations. Additionally, the approach described here, in principle, allows greater specificity in identifying the nature of the idiomatic features evident in a work or performance.

In Part I of this article, we describe the design and implementation of a computer model of a trumpet performer. The model is based on data collected from two actual performers. Given a monophonic musical passage, the model estimates the degree of difficulty according to nine performance criteria. Before making use of this model, we will attempt to evaluate its validity, and highlight various limitations and caveats in interpreting the resulting measures. At the outset, it is important for readers to be aware that our model contains many deliberate simplifications. Model outputs represent crude approximations of a highly complex and nuanced system of performer-instrument interactions. In Part II of this article, the model will be applied to the investigation of several works. In this second part, a distinction will be made between performance difficulty and performance idiomaticism; although these concepts are connected, we will argue that difficulty and idiomaticism are independent, and can be independently quantified. That is, a work may be both easy to perform and highly idiomatic to a given instrument, or the work might be difficult to perform and highly idiomatic, or the work might be difficult and unidiomatic, or easy and unidiomatic. The proposed technique for characterizing idiomaticism will be used to examine a number of musical works, including works composed by both trumpet players and non-players. To anticipate our conclusions, we will see that there are notable differences between trumpet works composed by performers and non-performers. Even when performers write virtuoso passages that are more difficult than passages written by nonperformers, there are telltale features that nevertheless suggest that the passages are well tailored to the instrument/performer duo. We will suggest that it is indeed possible to characterize idiomaticism quantitatively in ways that independently corroborate and refine common musical intuitions. These types of measurements may prove useful in a variety of scholarly tasks. For example, performance modeling may prove useful in analytic, historical, ethnomusicological, cognitive, and pedagogical applications.

\section{PART I: A MODEL OF TRUMPET PERFORMANCE DIFFICULTY}

One of the most natural criteria performers use when speaking about musical works is the degree of difficulty. Although difficulty is rarely a topic of discussion among those who analyze music, no performer is unaware of the fact that some works are very much more challenging than others. While degree of difficulty is not the same as idiomaticism, we will see later that a measure of performance difficulty is a pre-requisite for measuring instrumental idiomaticism.

A useful way of characterizing performance difficulty is to create a model of the performer/instrument interaction (Fiebrink, 2004; Gimenes \& Manzolli, 2006). Such a model would attempt to emulate the physical constraints of performance and to estimate the magnitude of the mechanical or physiological demands required by a given work or passage (MacKenzie \& Iberall, 1994). A practical way of modeling such an interaction is through a computer program. With appropriate knowledge of the 
instrument and the performer, it is possible to create a model that mimics aspects of the performance activity.

The complexity of such a model depends directly on the technical liberty available to the performer. For some instruments, it may be possible to perform a given passage in more than one way. On the violin and guitar, for example, a choice of strings may be available. On the piano, the pianist may choose to finger a passage in one of several ways: depending on the choice of fingering, a piano passage may be rendered either easier or more difficult (Parncutt, et al., 1997; Sloboda, et al., 1998). As the number of performance alternatives increase, the task of modeling a performance becomes more complex since the model must emulate sophisticated performance decisions made by the musician (Radicioni, 2005). In initiating this study we chose to avoid undue complexity by selecting an instrument whose degrees of freedom are relatively limited. Of Western orchestral instruments, the most constrained instruments (from the standpoint of performance alternatives) are the wind instruments. Typically, with woodwind and brass instruments, there is comparatively little choice in the mechanical aspects of how a given pitch may be generated. Although various notes on the trumpet can be played using alternative finger/valve combinations, these alternatives are rarely used in actual performance. Given its comparatively high level of technical restrictions, the trumpet was chosen for this study.

Conceptually, performance difficulty has often been divided into mechanical and interpretative aspects. In the case of the trumpet, the so-called mechanical aspects might include fingering, tonguing, embouchure, and breathing techniques. Interpretive aspects might include dynamic shading, phrasing, tone quality, and vibrato use. Of course such a division between mechanical and interpretive domains is suspect; in fact, it is contrary to much performance pedagogy - which presupposes their unity. Nevertheless, distinguishing the mechanical from the interpretive aspects of performance will significantly simplify our study. In defense of our use of this distinction, we may note that all analyses are partial descriptions of a complex whole. Any analytic description necessarily excludes a host of integral factors, and so may convey a false impression of the centrality or completeness of the analytic description. The pitfalls associated with circumscribing the discourse arise only if the tacit or operational distinctions are reified as "real" distinctions. Therefore, while acknowledging the artificiality of the distinction between "mechanical" and "interpretive" aspects of performance, we will nevertheless make use of this distinction as a fruitful point of departure. Although "interpretive" elements undoubtedly contribute to idiomaticism, no attempt has been made in our work to account for these aspects. In short, the model described below must be viewed as a naive "mechanical" model rather than a "mechanical/interpretive" model.

\section{SURVEY OF TRUMPET PERFORMANCE CONSTRAINTS}

The model was constructed on the basis of data collected from two trumpet performers. One performer was a professional orchestral musician and the second performer was an active amateur. The data collection entailed both survey information (i.e., estimates supplied by the performers) as well as physical measurements carried out by the authors. In general, the collected data pertained to four broad performance factors: fingering difficulty, tonguing difficulty, embouchure difficulty, and breathing difficulty.

With respect to fingering, the two trumpet players were provided with a chart identifying all possible transitions between two successive finger/valve combinations (see Table 1). For each finger/valve transition, the performers rated the relative degree of difficulty on a numerical scale ranging from 0 to 10 , where 10 represents the most difficult transition. Some transitions, such as the first valve followed by open position $(1 \rightarrow 0)$, were rated as having a low degree of difficulty. Other combinations, such as the first and third valves followed by the second valve $(1-3 \rightarrow 2)$, were rated as having a high degree of difficulty. ${ }^{[2]}$ Table 1 shows the average degree of difficulty for each of the possible finger/valve transitions - as judged by the two performers. Rows and columns represent, respectively, antecedent and consequent finger/valve combinations. 


\begin{tabular}{lllllllll}
\multicolumn{7}{c}{ Valve combination for the consequent note } \\
& \multicolumn{1}{c}{$\rightarrow 0$} & $\rightarrow 1$ & $\rightarrow 2$ & $\rightarrow 3$ & $\rightarrow 1-2$ & $\rightarrow 1-3$ & $\rightarrow 2-3$ & $\rightarrow 1-2-3$ \\
& & & & & & & & \\
$0 \rightarrow:$ & 0.0 & 1.0 & 1.0 & 1.9 & 1.5 & 3.0 & 3.0 & 3.5 \\
$1 \rightarrow:$ & 1.0 & 0.0 & 2.0 & 3.0 & 2.0 & 4.5 & 7.5 & 6.0 \\
$2 \rightarrow:$ & 1.0 & 1.5 & 0.0 & 5.3 & 3.0 & 9.5 & 6.0 & 9.0 \\
$3 \rightarrow:$ & 2.5 & 4.0 & 4.5 & 0.0 & 7.0 & 4.0 & 4.0 & 5.5 \\
$1-2 \rightarrow:$ & 1.5 & 1.5 & 2.3 & 7.5 & 0.0 & 6.0 & 6.0 & 5.0 \\
$1-3 \rightarrow:$ & 3.5 & 4.0 & 9.5 & 1.5 & 5.5 & 0.0 & 6.0 & 4.0 \\
$2-3 \rightarrow:$ & 2.5 & 6.0 & 5.5 & 4.0 & 5.0 & 5.5 & 0.0 & 3.8 \\
$1-2-3 \rightarrow: 3.0$ & 4.0 & 8.5 & 3.5 & 6.0 & 5.0 & 5.0 & 0.0
\end{tabular}

Table 1. Average difficulty for successive finger/valve combinations as judged by two trumpet players. Difficulty values range from 0.0 (trivial) to 10.0 (highest difficulty). $0=$ open position; $1=$ first valve; 1 $3=$ first and third valve, etc.

In addition to the fingering information, data were collected pertaining to the difficulty associated with pitch movement within registers. For each of three registers (notated G3-F\#4, G4-F\#5, G5 and above), the performers were asked to rate the difficulty associated with various ascending and descending melodic intervals. The performers were instructed to consider such factors as lip movement and diaphragm support - but to exclude fingering considerations. The mean scores of the two performers are shown in Table 2.

\begin{tabular}{lllllll} 
Interval & \multicolumn{2}{l}{ Low Register } & \multicolumn{2}{c}{ Middle Register } & \multicolumn{2}{c}{ High Register } \\
& $U p$ & Down & $U p$ & Down & $U p$ & Down \\
P1 & 1.0 & 1.0 & 1.0 & 1.0 & 5.8 & 5.8 \\
m2 & 1.5 & 1.5 & 1.0 & 3.5 & 5.8 & 6.5 \\
M2 & 1.5 & 1.5 & 1.3 & 3.5 & 6.3 & 7.0 \\
m3 & 1.5 & 2.0 & 2.0 & 4.5 & 7.8 & 8.0 \\
M3 & 2.5 & 2.0 & 2.0 & 4.5 & 8.0 & 8.3 \\
P4 & 2.0 & 2.5 & 4.5 & 6.5 & 8.3 & 8.5 \\
d5 & 3.5 & 5.0 & 5.5 & 7.5 & 9.5 & 10.0 \\
P5 & 3.0 & 6.0 & 5.0 & 7.0 & 9.5 & 9.0 \\
m6 & 4.0 & 6.5 & 7.5 & 9.0 & 11.0 & 10.0 \\
M6 & 4.0 & 6.5 & 8.0 & 9.0 & 11.0 & 10.0 \\
m7 & 5.5 & 8.5 & 9.0 & 10.0 & 11.8 & 12.0 \\
M7 & 5.5 & 8.5 & 9.5 & 10.5 & 11.0 & 12.0 \\
P8 & 7.0 & 11.5 & 12.0 & 12.0 & 2.5 & 12.0
\end{tabular}

Table 2. Average melodic-interval difficulty as judged by two trumpet players.

The performers were also asked to estimate the degree of difficulty associated with playing in each of the three registers for a prolonged period of time (i.e., endurance). Ratings are again on a scale of 0 to 10, and are reported in Table 3.

$\begin{array}{lc}\text { High register (notated G5 and above) } & 9.5 \\ \text { Middle register (notated G4-F\#5) } & 5.0 \\ \text { Low register (notated G3-F\#4) } & 4.25\end{array}$

Table 3. Average register-related difficulty as judged by two trumpet players.

In addition, the performers were asked to estimate the degree of difficulty associated with playing at various dynamic levels. Performers were told to assume that they would be required to sustain the given dynamic level for a prolonged period of time. The results are given in Table 4. 


$\begin{array}{ll}f f f & 9.0 \\ f f & 7.5 \\ f & 5.3 \\ m f & 2.5 \\ m p & 2.5 \\ p & 3.5 \\ p p & 5.0 \\ p p p & 7.0\end{array}$

Table 4. Average dynamic-level difficulty judged by two trumpet players.

Further information was gathered pertaining to lung capacity and diaphragm support. In this case physical measurements were made in order to determine the length of time a given pitch could be sustained. Three pitches were selected, each lying roughly in the middle of the traditional register designations: (notated) $\mathrm{Bb} 3, \mathrm{Bb} 4$, and $\mathrm{Bb} 5$. The measurements were repeated for each of four dynamic levels: $p p, m p, f, f f$. The results are shown in Table 5 .

$\begin{array}{lllll} & p p & m p & f & f f \\ & & & & \\ \mathrm{Bb5} & 11.0 & 15.0 & 10.5 & 9.0 \\ \mathrm{Bb} 4 & 40.0 & 31.0 & 21.0 & 14.5 \\ \mathrm{Bb3} & 35.5 & 23.5 & 14.0 & 10.5\end{array}$

Table 5. Average duration (in seconds) for sustained pitches.

Finally, a series of measures were made regarding tonguing. The performers were asked to tongue as fast as possible while producing distinct, well articulated notes. Measurements were made in each of three registers at each of four dynamic levels. Table 6 shows average tonguing speeds for single tonguing in terms of the elapsed time (in seconds) between successive articulations.

$\begin{array}{lllll} & p p & m p & f & f f \\ \text { High register } & 0.122 & 0.119 & 0.123 & 0.142 \\ \text { Middle register } & 0.163 & 0.123 & 0.126 & 0.142 \\ \text { Low register } & 0.125 & 0.132 & 0.128 & 0.132\end{array}$

Table 6. Average tonguing speeds in inter-note durations (seconds).

\section{Inter-Performer Consistency}

A simple measure of the concordance of two sets of data is provided by Pearson's coefficient of correlation. This allows us to characterize the level of agreement between the amateur and professional players' estimates of "degree of difficulty" as well as their physiological measures. If the independent responses of the two players fail to correlate strongly then less confidence can be ascribed to the pooled data. Table 7 shows the correlations between the data collected from the two performers. In general the correlations are high, although the performers' estimates of dynamic level difficult are notably less concordant than the other measures/estimates. The generally high positive correlation values suggest that both the amateur and professional performers broadly agree about what is "difficult" and display similar physiological constraints. Hence, it seems appropriate to average the values collected from the two performers - as we have done in the preceding Tables. 


Table
1
2
3
4
5
6

$\begin{array}{lcl}\text { Performance Factor } & \text { Correlation } & \text { df } \\ \text { Finger movement difficulty } & +0.83 & 62 \\ \text { Interval transition difficulty } & +0.77 & 77 \\ \text { Register-related difficulty } & +0.84 & 1 \\ \text { Dynamic difficulty } & +0.52 & 6 \\ \text { Duration for sustained pitches } & +0.89 & 10 \\ \text { Tonguing speeds } & +0.79 & 10\end{array}$

Table 7. Inter-Performer Correlations.

Having collected the above data, a simple instrument/performer model was constructed for the Bflat valve trumpet. The model accepts as input a notated musical passage. The model attempts to estimate the difficulty of the passage for each of seven technical aspects of performance: (1) pitch register, (2) dynamic level, (3) fingering, (4) tonguing, (5) embouchure endurance, (6) breathing, and (7) intervallic transitions. In the case of tonguing and breathing, two separate measures are defined for both aspects, raising the total number of measures to nine. As noted earlier, no attempt was made to model interpretive difficulty.

\section{PITCH REGISTER DIFFICULTY}

The model assigns pitches to one of three registers: high (notated G5 and above), middle (notated G4 to $\mathrm{F} \# 5$ ), and low (notated G2 to F\#4). For a given musical score, the register of each pitch is identified and the corresponding value from Table 3 determined. An average register difficulty for a musical passage is determined by dividing the sum of individual register difficulty values by the total number of notes in the passage. Note that the durations of the notes are ignored in this measure (see embouchure difficulty below).

\section{DYNAMIC LEVEL DIFFICULTY}

A similar approach is used to estimate dynamic level difficulty. The dynamic level for each successive note is identified and the corresponding value from Table 4 determined. In the case of diminuendos and crescendos, the dynamic level difficult is increased or decreased proportional to the base dynamic level. For example, a crescendo marking beginning from a prevailing fortissimo level causes an increase in dynamic level difficulty, whereas a crescendo beginning from a prevailing pianissimo causes a decrease in dynamic level difficulty. (Both written markings (e.g. "cres.", "decres.") and hairpin graphics ("<" or ">") are handled by the program.) An average dynamic level difficulty for a musical passage is determined by dividing the sum of the individual dynamic level difficulties by the number of notes in the passage.

\section{FINGERING DIFFICULTY}

For a given musical passage, fingering difficulty is calculated by assigning a difficulty value for each pair of successive notes according to the finger/valve transition values shown in Table 1 . The average fingering difficulty is calculated as the sum of all fingering difficulties divided by the number of sounding-note transitions in the work.

\section{TONGUING DIFFICULTY}

In general, the faster the performer must tongue, the more difficult tonguing becomes. Although we collected measures of double- and triple-tonguing speeds, we were unable to formalize an algorithm for deciding when to switch from single-tonguing to multiple-tonguing. Consequently, the current model does not attempt to decide when a particular passage should be played using double- or triple-tonguing.

The measurement of tonguing difficulty involves the classification of each note into one of four categories: (1) slurred, (2) easy, (3) difficult and (4) impossible. Notes in the middle of a slur require no tonguing, and so are simply ignored. Where the elapsed time between successive articulations is greater than 0.25 seconds, the tonguing is deemed to be "easy", and so no difficulty value is assigned.

Our measures of tonguing speed (Table 6) showed that the maximum tonguing speed is influenced by both register and dynamic level. The values in Table 6 are used by the model as boundaries to discriminate between difficult and impossible articulations. ${ }^{[3]}$ Where the inter-note durations are shorter 
than the fastest measured values, the notes were classified as "impossible". A running count of "impossible" articulations is tabulated by the model and this value is output as an independent index dubbed tongue-tied instances. However, the "impossible" notes are not assigned a difficulty value and do not participate in the tonguing difficulty measure.

Difficulty values for tonguing are assigned only to those notes that are classified as neither "slurred," "easy," or "impossible." As a simple estimate of difficulty, the assigned difficulties for these "difficult" notes is simply the duration of the note subtracted from 0.25 seconds. That is, when two tongued-notes are separated by nearly one-quarter second, they are assigned difficulty values near zero; shorter durations approaching the "impossible" threshold are assigned proportionally higher difficulty values.

In summary, the model provides two indices of tonguing difficulty. The first index, tongue-tied instances, maintains a simple tally of the number of articulations classified as "impossible." The second index focuses solely on those notes deemed to have "difficult" articulations. A total tonguing difficulty is defined as the sum of these "difficult" articulation values. In order to determine an average tonguing difficulty, the total tonguing difficulty is divided by the total number of articulations classified as "difficult." Note that "easy" articulations were explicitly excluded from calculations of the total and average tonguing difficulty. Consequently, a very difficult passage will not be characterized as less difficult merely because it is embedded in passages containing many easy tonguings. In short, tonguing difficulty is determined primarily by the most difficult passages found in a work.

\section{EMBOUCHURE ENDURANCE}

A simple estimate of embouchure endurance was calculated on the basis of judgments of register-related fatigue (Table 3). In general, embouchure endurance appears to be directly proportional to register, although the relationship appears to be exponential: low -4.25 ; middle -5.0 ; high -9.5 . For any given input passage the total embouchure endurance difficulty is calculated simply by multiplying the absolute amount of time (in seconds) spent in each of the three registers by the appropriate register fatigue constant. Rests have the effect of extending the embouchure endurance. No data were collected regarding recovery rates, however. Presumably, the recovery rate must be slower than the lowest fatigue rate while playing. An arbitrary recovery rate of 3 units per second was implemented as a constant. By way of illustration, if, over the course of a musical passage, five seconds is spent in the high register, ten seconds is spent in the middle register, one second is spent in the low register, and two seconds of rests occur, then the total embouchure difficult would be $(9.5 \times 5)+(5.0 \times 10)+(4.25 \times 1)-(3.0 \times 2)=95.75$. In our model, an average embouchure endurance difficulty is then calculated by dividing the total endurance difficulty by the duration of the piece.

\section{BREATHING DIFFICULTY}

In general, breathing may be regarded as "difficult" if the performer is frequently running out of breath, or is often on the verge of running out of breath. Two different measures of breathing difficulty are generated by the model. One measure (out-of-breath instances) is simply a tally of the number of occasions when the air supply becomes completely depleted. The second measure (average breathing difficulty) is defined as inversely proportional to the average air supply in the performer's lungs over the duration of the musical passage. That is, a passage is presumed to be difficult (from the perspective of breathing) when the performer is typically playing with little air in her/his lungs.

The model treats the lungs as a reservoir that may be depleted at various rates, or refilled at appropriate opportunities. Notes deplete the air supply in direct proportion to their durations. Our measurements (Table 5) indicated that both dynamic levels and register affect the depletion rates. Tones in the upper and lower register cause a faster depletion than mid-register tones; also higher dynamic levels exhaust the air supply faster than lower dynamic levels. Additional measurements were taken to determine the amount of time required to inhale completely. A full breath can be taken in about 1 second, although at least 0.25 seconds of rest is required in order to initiate inhaling.

The model assumes that the performer begins playing with full lungs and takes breaths whenever a rest period greater than 0.25 seconds occurs or whenever an explicit breath mark is notated in the score. Rests must be a minimum of 1.25 seconds in length in order to completely replenish the air supply. Rest periods between 0.25 and 1.25 seconds cause a partial replenishment in proportion to the duration. 
In our model, breathing difficulty is defined as the percent of the total lung capacity maintained on average throughout the passage minus 100 percent. For example, if a performer has a hypothetical lung capacity of 1 liter, and the average volume of air found in the player's lungs over the course of the work is 0.2 liters, then the breathing difficulty is defined as $100 \times(0.2 / 1.0 \times 100)$ or 80 . Breathing difficulty measures thus range between 0 and 100 where 100 represents the maximum breathing difficulty (i.e. "breathless" throughout the passage).

If the air supply becomes completely exhausted (i.e., run out of breath), the performance is interrupted and the model is forced to take a "quick" breath that replenishes two-thirds of the lung capacity. In such cases, the tally of out-of-breath instances is incremented.

\section{MELODIC INTERVAL DIFFICULTY}

In our model, melodic interval difficulty is estimated by measuring the interval transitions between the current and the previous pitch. A degree of difficulty is assigned to each interval on the basis of the data shown in Table 2. A total interval difficulty is defined as the sum of all the individual melodic interval difficulties. Average interval difficulty is calculated by dividing the total interval difficulty by the number of intervallic transitions in the musical passage.

\section{Computer Program}

The trumpet model outlined above was implemented using the AWK programming language (Aho, Kernighan \& Weinberger, 1988). The program accepts as input musical scores encoded in the Humdrum format (Huron, 1992, 1994, 1997, 1999, 2002; Selfridge-Field, 1997). Input information includes pitch, duration, dynamic markings, articulation, ornamentation, breath marks, tempo, slurring and phrasing. Ornaments are expanded by the program prior to calculating the difficulty measures. For any given musical input, the program outputs an average difficulty value for each of the seven performance factors described above. The program also outputs the number of "tongue-tied" instances (excessively fast articulations) and the number of "out-of-breath" instances (complete depletion of the air supply). In addition, an overall difficulty value is output representing a weighted sum of all the individual difficulty values. The method of calculation for this overall difficulty is described later in this article. A sample output of unnormalized measures is shown in Table 8.

$\begin{array}{ll}\text { Average breathing difficulty: } & 36.068 \\ \text { Out-of-breath problems: } & 9 \\ \text { Average tonguing difficulty: } & 13.995 \\ \text { Tongue-tied problems: } & 1 \\ \text { Average embouchure difficulty: } & 4.214 \\ \text { Average fingering difficulty: } & 0.829 \\ \text { Average dynamic difficulty: } & 3.968 \\ \text { Average range difficulty: } & 5.628 \\ \text { Average interval difficulty: } & 3.364 \\ \quad & \\ \text { Overall performance difficulty: } & 1.266 \\ \text { Total Duration of Performance: } & 118.6 \text { seconds. }\end{array}$

Table 8. Raw difficulty measures for Malcolm Arnold's Trumpet Concerto, movement III.

\section{Model Evaluation}

Given the many simplifying assumptions embodied in our trumpet model, it is essential that we attempt to characterize its validity. How well do the estimates of difficulty produced by the model coincide with independent difficulty ratings provided by experienced musicians? A convenient source of such ratings may be found in published conservatory curricula. To this end, we compared the program outputs against graded trumpet curricula for the Royal Conservatory of Music of Toronto (RCMT). Although conservatory curricula ratings cannot be regarded as infallible ratings of performance difficulty, one would be surprised if successive conservatory grades did not broadly reflect increasing levels of performance difficulty. 
Because our program was not designed to account for performance difficulties associated with musical interpretation, the selection of graded materials was purposely limited to trumpet études. We assumed that the difficulty associated with études would arise primarily from technical difficulties of performance, and that interpretive challenges would be relatively less important than is the case for nonétude works.

From each conservatory grade, two solo études were randomly selected from the published syllabus for trumpet. (Note: Grades I, III, V, and VII do not exist in the RCMT trumpet curriculum.) The selected works are identified in Table 9. Each of the works was encoded and difficulty measures generated by the program for each of the 9 factors described above. In general, we would predict that the difficulty measures should increase with successive grades for each factor. For example, we would expect the average breathing difficulty measures to be lowest for the lower grades and highest for the more advanced grades.

$\begin{array}{ll}\text { Grade } & \text { Composer } \\ \text { II } & \text { Endresen } \\ \text { II } & \text { Endresen } \\ \text { IV } & \text { Clodomir } \\ \text { IV } & \text { Clodomir } \\ \text { VI } & \text { Clodomir } \\ \text { VI } & \text { Clodomir } \\ \text { VIII } & \text { Balasanyan } \\ \text { VIII } & \text { Balasanyan } \\ \text { IX } & \text { Dubois } \\ \text { IX } & \text { Dubois } \\ \text { X } & \text { Charlier } \\ \text { X } & \text { Charlier }\end{array}$

$\begin{array}{lc}\text { Collection } & \text { Etude No. } \\ \text { Supplementary Studies } & 6 \\ \text { Supplementary Studies } & 12 \\ \text { 70 Little Studies } & 16 \\ 70 \text { Little Studies } & 25 \\ 70 \text { Little Studies } & 64 \\ 70 \text { Little Studies } & 65 \\ \text { Twenty Studies } & 1 \\ \text { Twenty Studies } & 4 \\ \text { 12 Etudes Variées } & 4 \\ \text { 12 Etudes Variées } & 5 \\ 36 \text { Etudes } & 2 \\ 36 \text { Etudes } & 16\end{array}$

Table 9. Test Etudes Selected from Royal Conservatory of Music (Toronto) graded curricula.

Each factor can be evaluated separately by correlating the difficulty measures for the given factor with the numerical conservatory grade. Table 10 shows the resulting correlations. For comparison, the inter-performer correlations (from Table 7) are also shown in parentheses.

\begin{tabular}{lcc} 
Performance Factor & \multicolumn{2}{c}{ Correlations } \\
& RCMT Grade & (Inter-Performer) \\
Fingering difficulty & +0.274 & $(+0.83)$ \\
Melodic interval difficulty & +0.463 & $(+0.77)$ \\
Emboucher/Duration & +0.259 & $(+0.89)$ \\
Tonguing difficulty & -0.595 & $(+0.79)$ \\
Tongue-tied instances & +0.301 & $(+0.79)$ \\
Register/Range difficulty & +0.301 & $(+0.79)$ \\
Breathing/Duration & +0.560 & $(+0.89)$ \\
Out-of-breath instances & +0.441 & $(+0.89)$ \\
Dynamic level difficulty & +0.015 & $(+0.52)$
\end{tabular}

Table 10. Comparison with Conservatory Graded Etudes, by Difficulty Factor.

With a single exception, all of the correlations are positive, indicating that the difficulty measures generally increase as the associated conservatory grade level increases. The single exception occurs for the average tonguing difficulty - suggesting either that the model provides an invalid estimate, or perhaps that the increasing difficulty of the études may be attributed primarily to factors other than tonguing. However, the positive correlation for the independent tongue-tied instances implies that the average tonguing difficulty measure may simply be unreliable.

The right-most column of Table 10 reproduces the inter-performer correlations measured earlier (Table 7). If performers tend not to agree in their difficulty judgments (or measurements), then we cannot expect a derived algorithmic measure to do any better when estimating difficulty. Conversely, if the 
performers are in close agreement concerning a given difficulty factor, then we might expect a better performance for the derived measurement factor. A reassuring pattern would exist if the correlation values between the various measurement methods and the conservatory grades were similar to the inter-performer correlations for each measurement. That is, where the performers tend to diverge in their difficulty judgments the derived model measure would similarly display less validity; where the performers agree in their judgments, the derived model measure would display greater validity. A simple test of this prediction is to correlate the two sets of correlations shown in Table 10 . The result is $+0.37(\mathrm{df}=7)$ which, although not statistically significant, is mildly reassuring since it is positive.

\section{Estimating Overall Difficulty}

Although the model provides independent outputs for each of nine difficulty measures, it is useful to attempt to estimate an overall difficulty for a given musical passage. Combining the various factors into a single measure is fraught with potential pitfalls. Without further physiological investigations we can proceed only by making an additional assumption that the overall difficulty of (technical) performance can be estimated as the weighted sum of the difficulties in each of the nine performance factors identified above. There are undoubtedly interactions between these performance factors (such as the coordinated action of fingers and tongue), however no attempt was made to simulate these complex relationships.

In our model, an overall difficulty value was calculated as the weighted sum of the nine factors identified above. Before combining the measures for the different factors, each measure was independently scaled so that their numerical ranges were commensurate. For example, the raw average fingering difficult scores for all twelve études were found to range between 1.1 and 3.8, whereas the raw average breathing difficulty scores for these works ranged between 15.9 and 175. The ranges for each factor were statistically normalized using the scores for the twelve trumpet études as a sample repertoire.

Determining the proportional contribution of each factor was done heuristically. An initial set of weightings was assigned purely by intuition - in conjunction with advice offered by one of the performers. Given the number of degrees of freedom, no attempt was made to optimize these weightings. The percent weightings are shown in Table 11. Since the measure of average tonguing difficulty displayed a negative correlation with the test sample of trumpet études, this measure was omitted from the overall difficulty calculation. The overall performance difficulty is intended to provide an aggregate estimate of the (noninterpretive) performance demands arising from a given passage.

$\begin{array}{lc}\text { Factor } & \text { Weighting (\%) } \\ \text { breathing difficulty } & 15 \\ \text { out-of-breath problems } & 10 \\ \text { tonguing difficulty } & 0 \\ \text { tongue-tied instances } & 10 \\ \text { embouchure difficulty } & 15 \\ \text { fingering difficulty } & 10 \\ \text { dynamic level difficulty } & 5 \\ \text { range difficulty } & 10 \\ \text { interval difficulty } & 25\end{array}$

Table 11. Weighting coefficients for nine performance factors.

Using these weightings, the overall difficulty levels for the twelve conservatory études were calculated. The output values necessarily have a mean of zero and a standard deviation of 1 . In order to avoid negative difficulty values and to increase the data spread, the output values were multiplied by two and an offset of 1 added. This means that the average difficulty for the études will be 1 , with somewhat more spread. ${ }^{[4]}$ These values are shown in Table 12. 


$\begin{array}{cc}\text { RCMT Grade } & \text { Study No. } \\ \text { II } & 6 \\ \text { II } & 12 \\ \text { IV } & 16 \\ \text { IV } & 25 \\ \text { VI } & 64 \\ \text { VI } & 65 \\ \text { VIII } & 1 \\ \text { VIII } & 4 \\ \text { IX } & 4 \\ \text { IX } & 5 \\ \text { X } & 2 \\ \text { X } & 16\end{array}$

Composer
Endresen
Endresen
Clodomir
Clodomir
Clodomir
Clodomir
Balasanyan
Balasanyan
Dubois
Dubois
Charlier
Charlier

Overall Performance Difficulty
0.59
0.50
0.46
1.25
0.99
1.23
1.29
1.03
1.20
0.97
1.06
1.43

Table 12. Overall performance difficulty measures for graded trumpet etudes.

The grade designations for the twelve études were compared to the corresponding overall difficultly values, and the coefficient of correlation was found to be +0.71 . This correlation indicates that half of the variance in the grade assignments for these works is accounted for by the weighted factors included in our overall difficulty measure.

In general, the results of the validation study suggest that the performance measures examined here appear to hold some merit as estimates of trumpet performance difficulty. Although far from ideal, these simple measures provide a crude index by which the difficulty of passages for trumpet may be estimated. The analytic utility of such a measure is demonstrated in Part II.

\section{PART II: ANALYTIC APPLICATIONS}

\section{Measures of Performance Difficulty in Selected Trumpet Works}

The trumpet-performance model developed in Part I was employed in the study of five compositions. Two works were written for the B-flat trumpet by a trumpet player: Malcolm Arnold's Trumpet Concerto and Fantasy for Trumpet; two further works were written for the B-flat cornet by cornet players: Guillaume Balay's cornet solo Prelude et Ballade and Herbert Clarke's Stars in a Velvety Sky; and one composition for B-flat trumpet was written by a non-trumpet player: Paul Hindemith's Sonate für Trompete in B und Klavier (1939). Table 13 shows the overall performance difficulties for these five pieces as estimated by the trumpet model described in Part I. According to our trumpet model, of the works examined, Malcolm Arnold's Fantasy Opus 100 is by far the most difficult (2.57), followed by Herbert Clarke's Stars in a Velvety Sky (1.77). The first and third movements of Paul Hindemith's Sonate are also somewhat difficult $(1.53 ; 1.37)$. Recall that an overall difficulty value of 1.0 corresponds with the average difficulty for the sample of conservatory études used in the validation study.

In general, the results of Table 13 are of only marginal analytic interest. Nevertheless, these difficulty measures can be employed as a useful springboard from which inferences can be made regarding the degree of idiomaticism exhibited by a work.

$\begin{array}{llcc}\text { Composer } & \text { Title } & \text { Movement } & \text { Overall Performance Difficulty } \\ \text { Arnold } & \text { Fantasy for Trumpet } & & 2.57 \\ \text { Arnold } & \text { Trumpet Concerto } & \text { I } & 1.35 \\ & & \text { II } & 0.96 \\ & & \text { III } & 1.27 \\ \text { Balay } & \text { Prelude et Ballade } & & 1.07 \\ \text { Clarke } & \text { Stars in a Velvety Sky } & & 1.77 \\ \text { Hindemith } & \text { Sonate für Trompete } & \text { I } & 1.53 \\ & \text { in B und Klavier } & \text { II } & 0.73 \\ & & \text { III } & 1.37\end{array}$

Table 13. Estimates of overall performance difficulties for selected trumpet works. 


\section{Performance Difficulty versus Idiomaticism}

It is tempting to assume that an "idiomatic" work is a work that is easy to perform. However, a work that is easily performed on a given instrument is also likely to be easy to perform on other instruments as well. An important distinction can be made between the performance difficulty of a work and its degree of idiomaticism.

A difficult work may be defined as a work that places stringent demands on the performer, such as extraordinary physical endurance, highly refined or accurate motor skills, taxing motor coordination, or other awkward or strenuous tasks. By idiomatic, we mean that, of all the ways a given musical goal or effect may be achieved, the method employed by the composer/musician is one of the least difficult. That is, the effect is produced with comparative or relative ease. Consider, by way of example, the effect of key on performance difficulty. Suppose we were to transpose a work through all twelve pitch-classes, and compare the difficulty for all transpositions. If a work had been written in the key of E major, and E major turned out to be the most difficult of all possible keys, then it would be difficult to claim that the work has been arranged idiomatically. On the other hand, if we found that the key of E major exhibited the lowest possible difficulty score, then this would lend weight to a claim that the work was created with the instrument in mind.

\section{TRANSPOSITION IDIOMATICISM}

Figures 1 and 2 show the effect of transposition on fingering difficulty estimates for the Arnold, Balay and Clarke works. The graphs cover a range of plus or minus one octave. The actual key of composition is plotted in the center of the graph. Notice, first of all, that the fingering difficulty shows a general tendency to fall as the work is transposed up in pitch. Brass players will recognize that this is a simple consequence of the way the harmonics and valves interact. As a work is transposed higher, there is less need to use some of the more difficult finger combinations.

Superimposed on this general downward trend are local fluctuations in difficulty depending on the particular key. With one exception, there is a notable minimum evident at zero transposition (i.e., the original key of composition). The one exception occurs for the slow second movement in Arnold's trumpet concerto - a movement that Table 13 shows has a relatively low overall difficulty (0.96). The predominance of local dips at zero transposition suggests (but does not prove) that the composers chose a key that facilitates performing the work.

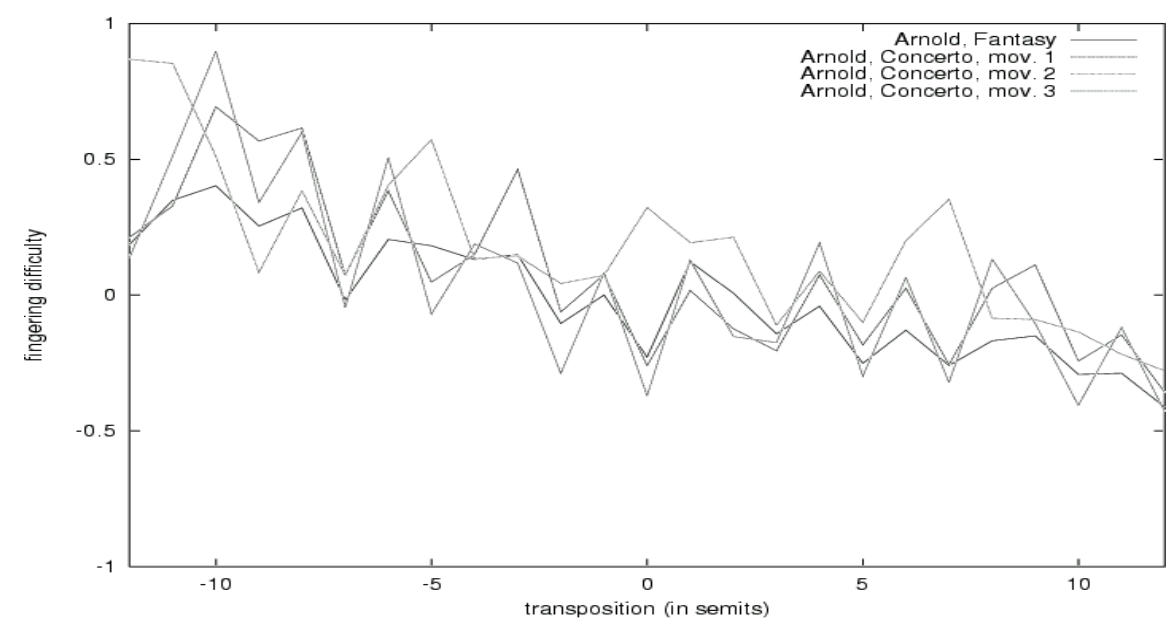

Figure 1. Effect of transposition on fingering difficulty for Malcolm Arnold's Fantasy and three movements from Arnold's Concerto. A general downward trend is evident as the work is transposed higher in pitch. (This trend is an artifact of the greater fingering choice for higher harmonics.) Local fluctuations in difficulty show that fingering is especially easy for three of the four pieces when the works are performed in the original key. The exception is the second (slow) movement of Arnold's Concerto. Transpositions span two octaves. 


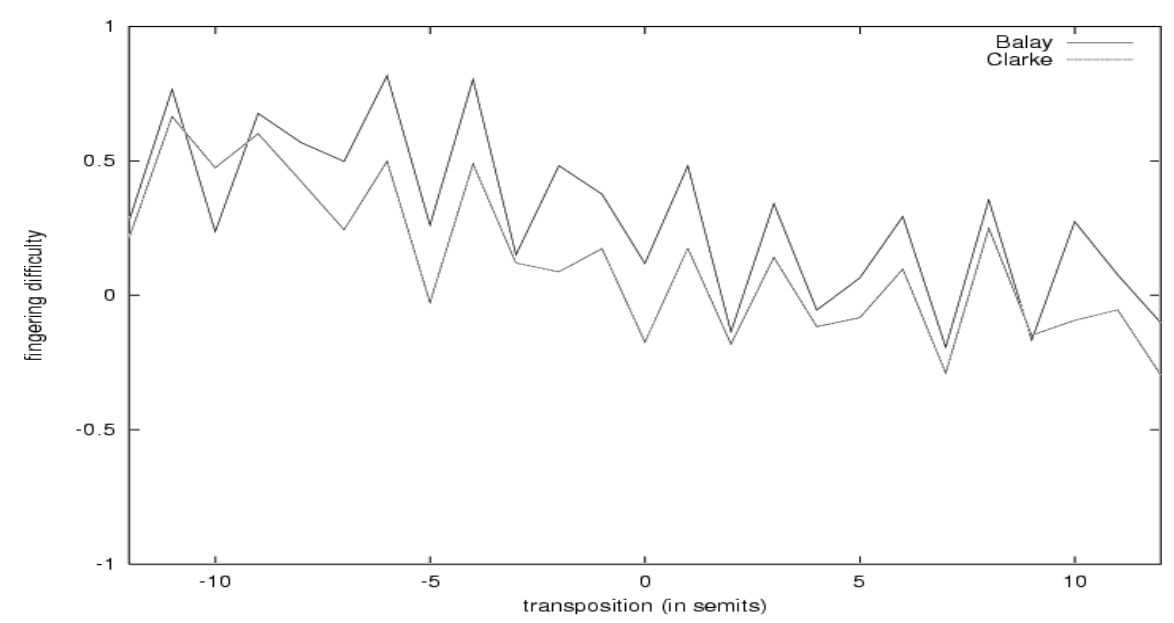

Figure 2. Effect of transposition on fingering difficulty for Guillaume Balay's cornet solo Prelude et Ballade and Herbert Clarke's Stars in a Velvety Sky. Local fluctuations in difficulty suggest that Clarke's work is relatively well situated for key. Balay's work is more equivocal.

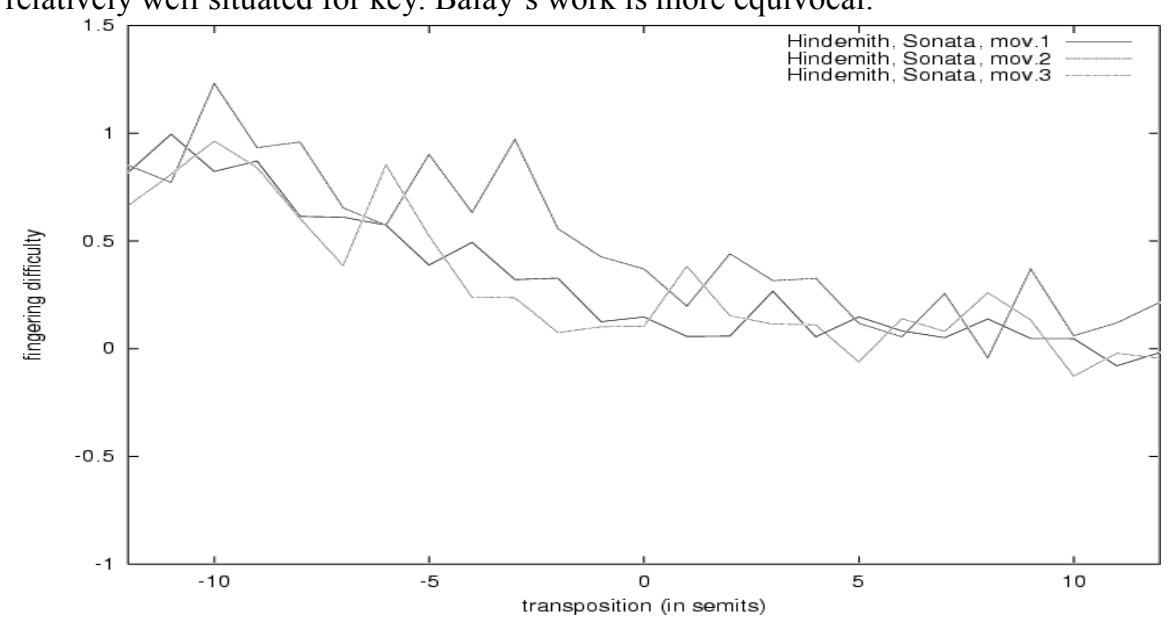

Figure 3. Effect of transposition on fingering difficulty for three movements from Paul Hindemith's Sonate für Trompete in B und Klavier. Transposition level appears to have little effect on fingering difficulty.

Figure 3, by contrast, shows the comparable results for Paul Hindemith's Trumpet Sonata. Here there is no clear effect of key, nor is there any notable dip coinciding with the key chosen by Hindemith.

\section{TEMPO IDIOMATICISM}

Another way of examining possible idiomatic design in these works is to observe the effect of changing the tempo. In the case of wind instruments, an especially slow rendition of a work is apt to engender breathing difficulties, whereas a faster rendition is apt to engender tonguing and other problems. Apart from considerations of musical interpretation, it may be the case that for some musical works there exists an optimum tempo where no single performance factor is especially taxing.

In all of the works studied, recommended metronome markings are specified throughout the published scores. In the following graphs, we systematically changed the tempi of the works in a range from $50 \%$ below the notated tempo to $50 \%$ above the notated tempo. Figures 4 and 5 show the effect of tempo on overall difficulty for the works written by trumpet virtuosi. In the case of Malcolm Arnold's works, tempo seems to have little effect - except for the lively first movement of his trumpet concerto, which shows a notable increase in difficulty when the tempo is increased by roughly 25 percent. 


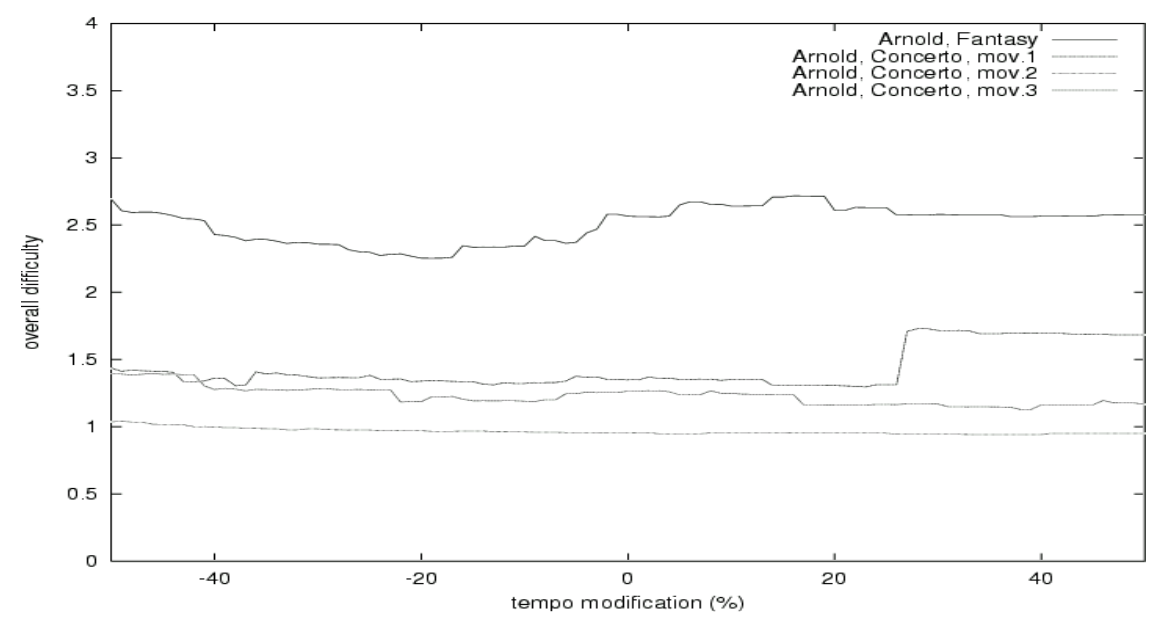

Figure 4. Effect of changing tempo on overall difficulty for Malcolm Arnold's Fantasy and three movements from Arnold's Concerto. Graphs show little change in difficulty as tempo is increased or reduced from the recommended tempo. The first movement of Arnold's Concerto, shows an increase in difficulty when the tempo is increased by about 25 percent.

Figure 5 shows the results for Balay's Prelude et Ballade and Clarke's Stars in a Velvety Sky. These works show a marked increase in overall difficulty just above the notated tempo. In the Clarke work, the increase occurs about 15 percent above the recommended tempo, whereas in the Balay the increase occurs about 5 percent above the recommended tempo. Incidentally, this same pattern of a large increase in difficulty occurring just above the recommended metronome setting is also evident in the majority of trumpet études discussed earlier.

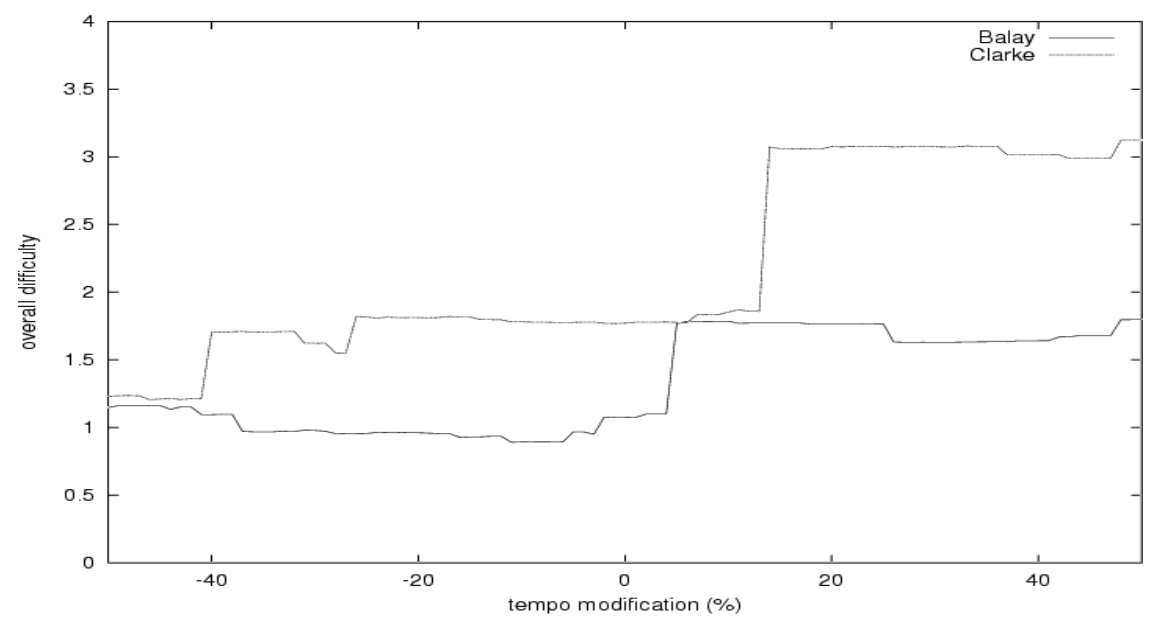

Figure 5. Effect of changing tempo on overall difficulty for Guillaume Balay's Prelude et Ballade and Herbert Clarke's Stars in a Velvety Sky. In the Balay work, a significant increase in difficulty (due to tonguing) occurs when the tempo is increased by about 5 percent. In the Clarke work, a significant difficulty increases dramatically where the tempo is increased by about 15 percent.

Once again, Hindemith's Sonate for trumpet (Figure 6) provides a seemingly marked contrast to the other works. In the first and third movements, the difficulty declines slightly as the tempo is increased suggesting that the principal difficulty in these movements is breathing rather than articulation. Only the agitated second movement ("Massig bewegt") shows the abrupt increase in difficulty evident in other works, and here the effect is present only after an increase in tempo of about 20 to 25 percent. 


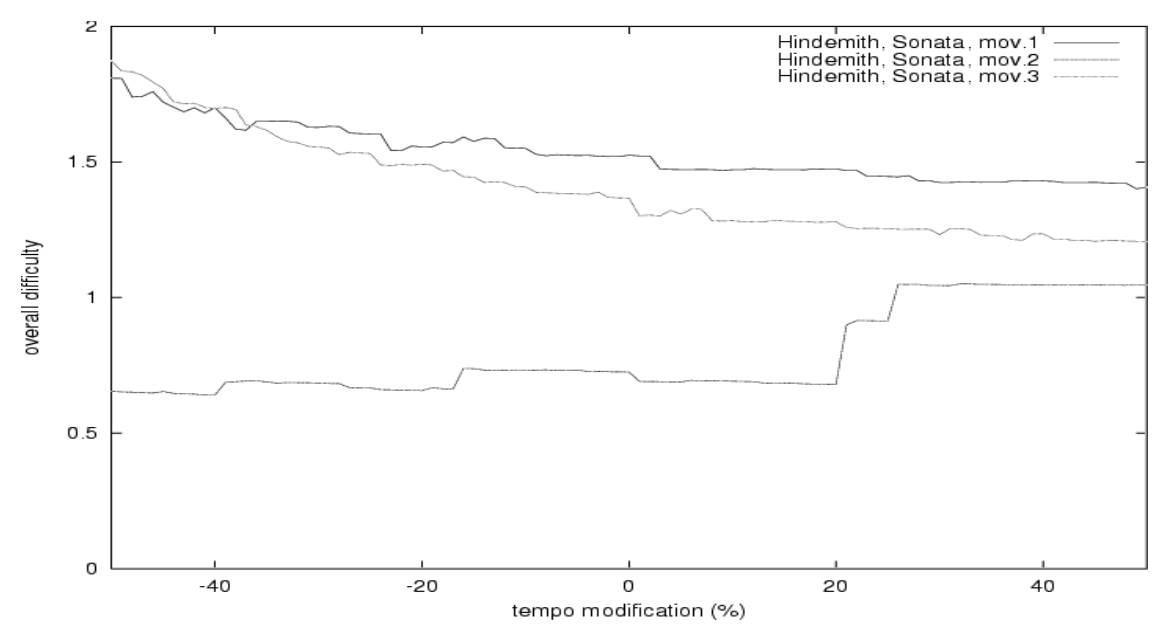

Figure 6. Effect of changing tempo on overall difficulty for three movements from Paul Hindemith's Sonate für Trompete in $B$ und Klavier. The first two movements appear to get gradually easier with increasing tempo. In the third movement, an increase in difficulty appears at roughly 20 percent above the recommended tempo. (Note that the overall difficulty scale for Fig. 6 is lower than for Figures 4 and 5.)

By way of summary, we have seen that the choice of key and the choice of tempo can have a considerable impact on the overall performance difficulty for a work. In the case of our sample of works by virtuosi composers, we saw evidence that suggests the choice of keys and tempi may approach optimal values. That is, for many movements, the composer has chosen the best possible key or tempo - from the point of view of reducing the performance difficulty. In the case of works composed by a non-trumpet player, the choices of key and tempo appear to be independent of considerations of performance difficulty. In light of the very small number of works examined in this study, however, this conclusion should be regarded as highly tentative and provisional.

In our analyses here, we have only examined key-related and tempo-related idiomaticism. One could similarly examine the effects of (say) dynamics, articulation, phrasing, or other musical treatments. For example, one could systematically increase (and decrease) the dynamic markings in order to determine the dynamic level that best minimizes performance difficulty. It bears emphasizing that measures of performance ease and measures of instrumental idiomaticism cannot be regarded prima facie as indices of compositional merit. Difficult works are not necessarily better than easy works, and idiomatic works are not necessarily better than unidiomatic works. (Indeed, one could argue that the above graphs show that Hindemith was more concerned with "musical" issues rather than "performance" issues.) Only if the composer's explicit goal is to create a highly idiomatic work might such measures be construed as having a bearing on the evaluation of a composition. In Hindemith's case, one might argue that his own espoused philosophy of Gebrauchmuzik renders him susceptible to criticism. However, in this study we have examined only a single work by Hindemith, so generalizing from this one work is problematic. In addition, contrasting Hindemith directly with virtuoso performer/composers is perhaps unfair. A more appropriate comparison might be with other non-trumpet composers of comparable compositional reputation.

Finally, note that there are occasionally good reasons for a composer to write explicitly difficult works. Composers have sometimes claimed that they intentionally write difficult music in order to ensure that their works are performed solely by expert performers. In addition, as Bernard Holland (1999) has pointed out, difficulty itself can be a handy muse.

\section{CONCLUSION}

A musical composition may be regarded as an artifact whose construction is shaped by several concurrent goals and constraints. Compositional goals may include formal or aesthetic objectives, inter-textual references, personal statements, perceptual concerns, affective goals, religious or liturgical function, social or political interests, or even monetary needs - to name a few. Compositional constraints may include commission requirements (such as composing music for a coronation procession), limitations of 
performance time, rehearsal time, playability of the music, availability of certain instrumental resources, availability of especially gifted performers, characteristics of the performance space, impending deadlines, budget restrictions, competing activities, ill health, and many other possible factors.

In an ideal world, a thorough analysis of a work would seek to identify which combination of factors (goals, constraints and opportunities) influenced the organization of the work, and to characterize the relative importance of each factor in shaping the work's creation. In this study we have focused on two performance-related factors: the difficulty of performance, and the degree of idiomaticism. By modeling a performer/instrument interaction it is possible to characterize musical passages according to the performance difficulty for a given instrument and to compare the difficulty of various works. The model described in this paper makes a large number of simplifying assumptions. Most notably, the model fails to deal with the interpretive dimensions of performance, and no effort was made to handle the interactions between the various physical and physiological factors that are sure to be present. Although the model used in this paper produces relatively crude measurements, more detailed kinesthetic knowledge might be expected to lead to more refined measurements.

In the case of instrumental idiomaticism, we noted that idiomaticism might be defined as the degree to which a given means of achieving a certain musical goal is significantly easier than other hypothetical means. For example, in the third movement of Arnold's trumpet concerto, we were able to show that, of all possible keys, the actual key of the work minimizes the difficulty associated with successive valve/finger combinations on the B-flat trumpet. In short, it is possible to use performance/instrumental models to identify aspects of musical organization that may be accounted for by idiomatic concerns.

Formally, one might propose a numerical index that expresses idiomaticism as a normalized difficulty value - comparing the difficulty for a prescribed performance condition with the difficulty scores for other possible performance arrangements. For example, with regard to tempo, one might calculate a normalized difficulty value for the recommended tempo by determining the mean and standard deviation for the values spanning some range of tempos (say, from -50 percent to +50 percent). A large negative $z-$ score would be symptomatic of a high degree of idiomaticism. In the case of trumpet fingering, it would be appropriate first to remove the effect of tessitura on fingering difficulty. Fitting a smooth curve through the data, normalized scores can be calculated by first determining the deviation from the tessitura trend data at each transposition level. Calculating a z-score makes it possible to estimate the degree of idiomaticism independent of the overall difficulty of a work or passage. That is, whether a passage is easy or difficult to perform has no direct bearing on whether the passage is idiomatic. The key comparison is the degree of difficulty compared with other possible performance conditions. What makes something idiomatic is not that it is easy to play, but that it is easier to play given the specific prescribed circumstances compared with other possible performance circumstances. A further advantage of using normalized scores is that they allow a direct estimate of the probability of observing a value by chance. That is, z-scores allow the music scholar to estimate the likelihood of making a false claim that something is idiomatic when it is not.

A number of assumptions were made in the creation of our trumpet model, and it is important that these assumptions are clearly recognized. The current model divorces mechanical aspects of performance from interpretive aspects. The model further assumes that difficulties arising from interpretation contribute less to the overall performance difficulty than mechanical performance aspects. The current model assumes that overall mechanical difficulty can be estimated as the linear sum of several components; this assumption ignores possible interactions between performance factors. The overall difficulty measure is based on estimated weightings assigned to each performance aspect; these weightings have no empirical status. Similarly, the recovery rate associated with embouchure endurance was an estimated value that was not based on an actual measurement. Furthermore, it was assumed that single tonguing is always used. The current model has no built-in "intelligence" to determine appropriate breathing points - not associated with a rest. As a result, non-rest breathing points must be explicitly marked.

Despite the limitations of the specific model described in this study, the overall approach may prove useful in various analytic, historical, ethnomusicological, pedagogical, and cognitive applications. In the first instance, our approach shows that it is possible to distinguish idiomaticism from performance difficulty. In addition, our approach may lead to insights pertaining to compositional processes. For example, idiomatic clues can lend weight to hypotheses that a given work was initially conceived for alternative resources, or that the composer used a particular instrument during composition. Conversely, the total absence of idiomatic features may be cited as evidence supporting a more formal or abstract musical origin. 
In the analyses described here, we dealt with complete works or movements. However, difficulty and idiomatic measures can be traced dynamically throughout a work or movement and related to other musical features. For example, it is possible that particular harmonic, or melodic events arise due to idiomatic concerns, constraints, or opportunities. Detailed study of the "micro-structure" of performance difficulty might prove to be rewarding. ${ }^{[5]}$

\section{NOTES}

[1] Please address all correspondence to: David Huron, School of Music, 1866 College Rd., Columbus, OH, 43210, U.S.A.

[2] Since finger/valve combinations associated with the right hand often result in slide movements accommodated by the left hand, the performers were instructed to take into account both left and right hand movements.

[3] Data were not gathered for the dynamic levels $p p p, p, m f$, and $f f f$. However, based on the information collected, additional time values were calculated by interpolation or extrapolation.

[4] N.B. This scaling is a linear mathematical transformation and so has no affect on correlational values and other measures.

[5] An earlier version of this research was presented at the 1995 Society for Music Perception and Cognition Conference, Berkeley, California.

\section{REFERENCES}

Aho, A.V., Kernighan, B.W., \& Weinberger, P.J. (1988). The AWK Programming Language. New Jersey: Addison-Wesley Publishing Company.

Arnold, M. (1969). Fantasy for B flat Trumpet [Opus 100]. London: Faber Music Ltd.

Baily, J. (1985). Musical structure and human movement. In: I. Cross \& R. West (Eds.), Musical Structure and Cognition. London: Academic Press, pp. 237-258.

Balasanyan, S.A. (n.d.). Twenty Studies for Trumpet Solo. New York: International Music Company (\#1169).

Balay, G. (n.d.). Prelude et ballade. Cornet Solo with Piano Accompaniment. New York: Belwin Inc.

Charlier, T. (1946). Trente-six études transcendantes pour trompette. Paris: Alphonse Leduc.

Clarke, H.L. (n.d.) Stars in a Velvety Sky. Solo B-flat Cornet. New York: Carl Fischer.

Clodomir, P.F. (n.d.). 70 Little Studies for Trumpet. New York: International Music Company (\#1389).

DeWitt, M.F. (1998). The Cajun and Zydeco music and dance scene in northern California: Ethnicity, authenticity, and leisure. PhD dissertation, Music Dept. University of California, Berkeley.

Dreyfus, L. (1998). Idiomatic betrayals: François Couperin as composer for the viol. In: d'Huguette Dreyfus (ed.), François Couperin: nouveaux regards: sous la direction (pp. 205-221) Paris: Klincksieck.

Dubois, P.M. (n.d.). Douze études variées pour trompette. Paris, Alphonse Leduc.

Endresen, R.M. (1939). Supplementary Studies for Cornet or Trumpet. Chicago: Rubank, Inc. 
Fiebrink, R. (2004). Modeling flute fingering difficulty. Senior Distinction Project. School of Music, Ohio State University.

Gibson, J.J. (1977). The theory of affordances. In: R. Shaw \& J. Bransford (Eds.), Perceiving, Acting, and Knowing. Hillsdale, New Jersey: Lawrence Erlbaum Associates, pp. 67-82.

Gimenes, M. \& Manzolli, J. (2006). Técnicas e "affordances” instrumentais: um modelo para a performance e a criação na música contemporânea. In: XVI Congresso da Associação Nacional de Pesquisa e Pós-graduação em Música. Brazil: ANPPOM, pp.288-293.

Henry, O. W. (1970). The electro-technology of modern music. Arts in Society, 7(1): 20-26.

Hindemith, P. (1940). Sonate für Trompete in B und Klavier. Mainz: B. Schott's Sohne (ED 3643).

Holland, B. (1999). When composers make it hard, fright and strain become muses. New York Times, Tuesday, June 1, 1999, p. B1.

Horton, C. (1986). The Identification of Idiomatic Writing for the Horn. DMA dissertation., School of Music, University of Wisconsin, Madison.

Huron, D. (1992). Design principles in computer-based music representation. In A. Marsden \& A. Pople (eds.), Computer Representations and Models in Music. London: Academic Press, pp. 5-59.

Huron, D. (1994). The Humdrum Toolkit; Reference Manual. Menlo Park, California: Center for Computer Assisted Research in the Humanities.

Huron, D. (1997). Humdrum and Kern: Selective feature encoding. In E. Selfridge-Field (Ed.), Beyond MIDI: The Handbook of Musical Codes. Cambridge, Massachusetts: MIT Press, pp. 375-401.

Huron, D. (1999). Music Research Using Humdrum: A User's Guide. Stanford, California: Center for Computer Assisted Research in the Humanities.

Huron, D. (2002). Music information processing using the Humdrum Toolkit: Concepts, examples, and lessons. Computer Music Journal, 26(2): 15-30.

Jiranek, J. (1971). Statistika jako pomocny nastroj intonacni analyzy. [Statistics as a tool in analysis of socalled idiomatic characteristics.] Hudebni veda, 8(2): 165-82.

Le Guin, E.C. (1997). 'As my works show me to be': Physicality as compositional technique in the instrumental music of Luigi Boccherini. PhD dissertation, University of California, Berkeley.

MacKenzie, C.L. \& Iberall, T. (1994). The Grasping Hand. Amsterdam: North-Holland: Elsevier Science.

Mohr, W. (1972). Die Klavierfassung von Beethovens Violinkonzert. Österreichische Musikzeitschrift, 27(2): 71-75.

Morehen, J. (1994). Aiding authentic performance: A fingering databank for Elizabethan music. Computing in Musicology, 9, 81-92.

Norman, D. (1988). The Design of Everyday Things. New York: Basic Books.

Parkins, R. (1983). Keyboard fingering in early Spanish sources. Early Music, 11(3): 323-331.

Parncutt, R., Sloboda, J.A., Clarke, E.F., Raekallio, M. \& Desain, P. (1997). An ergonomic model of keyboard fingering for melodic fragments. Music Perception, 14, 115-138. 
Radicioni, D.P. (2005). Computational modeling of fingering in music performance. PhD dissertation, Department of Psychology, University of Torino, Italy.

Richardson, J. S. (1996). B.B. King: Analysis of the artist's evolving guitar technique. American Music Research Center Journal, 6, 89-107.

Sachs, K. (1913). Real-Lexicon der Musikinstrumente. Berlin: Julius Bard.

Sarris, H. \& Tzevelekos, P. (2008). "Singing like the Gaida (Bagpipe)": Investigating relations between singing and instrumental playing techniques in Greek Thrace. Journal of Interdisciplinary Music Studies, 2(1-2): 33-57.

Selfridge-Field, E. (1997). Beyond MIDI: The Handbook of Musical Codes. Cambridge, Massachusetts: MIT Press.

Shao, T. T. (1997). Franz Liszt's transcription of Johann Sebastian Bach's Prelude and Fugue in A minor (BWV 543). DM dissertation., Louisiana State University.

Shepherd, R.C. (1995). The emergence of a pivotal role for the thumb in keyboard fingering during the early eighteenth century and its subsequent impact on pianistic idiom. DMA dissertation, University of Illinois, Urbana-Champaign.

Sloboda, J.A., Clarke, E.F., Parncutt, R. \& Raekallio, M. (1998). Determinants of fingering choice in piano sight-reading. Journal of Experimental Psychology: Human Perception and Performance, 24, 185-203.

Sudnow, D. (1978). The Ways of the Hand; The Organization of Improvised Conduct. Cambridge, Massachusetts: Harvard University Press.

Sudnow, D. (1979). Talk's Body. New York: Alfred A. Knopf, Inc.

Uexküll, J. von (1920). Kompositionslehre der Natur: Biologie als undogmatsche Naturwissenschaft. Ausgewählte Schriften. T. von Uexküll (Ed.). Frankfurt am Main; reprinted 1980, Berlin: PropyläenVerlag.

Ung, L. (1981). Indicators of early piano writing in the Haydn sonatas. In J.P. Larsen, H. Serwer \& J. Webster (eds.), Haydn Studies. New York and London: Norton, pp. 323-326.

Walser, R. (1993). Out of notes: Signification, interpretation, and the problem of Miles Davis. Musical Quarterly, 77(2): 343-365.

Yu, A. S.-F. C. (1977). The melodic concepts in three genres of Chinese songs: A study of the relationship between language and music. PhD dissertation, Music Dept., Columbia University.

Yung, B. (1984). Choreographic and kinesthetic elements in performance on the Chinese seven-string zither. Ethnomusicology, 28, 505-517. 